\title{
Membangun orientasi pelanggan untuk meningkatkan salesperson consulting performance
}

\author{
Ida Bagus Nyoman Udayana* \\ Jurusan Manajemen, Fakultas Ekonomi, Universitas Sarjanawiyata Tamansiswa Yogyakarta, \\ Indonesia \\ ibn.udayana@yahoo.co.id \\ Titisari Herniwati \\ Jurusan Manajemen, Fakultas Ekonomi, Universitas Sarjanawiyata Tamansiswa Yogyakarta, \\ Indonesia \\ Tsariherniwati12496@gmail.com \\ Ida Ayu Purnama \\ Jurusan Akuntansi, Fakultas Ekonomi, Universitas Pembangunan Nasional Veteran, \\ Yogyakarta, Indonesia \\ ida.ayupurnama@upnyk.ac.id
}

*Penulis Korespondensi

Submitted: Oct 26, 2019; Reviewed: Mar 08, 2020; Accepted: Apr 04, 2020

\begin{abstract}
The purpose of this paper is to analyze the influence and relationship between variables that can improve sales consultant performance. For this reason, an understanding of customer needs and desires is something that is urgent for the success of an organization. An organization that can properly understand customer tastes can directly or indirectly influence the performance of salesperson. Through the training included here is sharing experiences with colleagues, especially salespeople who are considered outstanding. This research method uses a sample of 150 salesperson who perform the main task of selling. Purposive sampling is used for sampling techniques. The data that has been collected is carried out screening and trimming data. Data screening is carried out to test the consistency of respondents' answers by looking at extreme standard deviations. While trimming data is intended to test the consistency of the contents of respondents' answers between closed answers and open answers. Validity and reliability tests are conducted to test the validity and consistency of the respondents' answers. The results showed that, market orientation, sales adaptation, and developing customer orientation had a significant positive effect on sales consultant performance. The customer orientation variable most influences the performance of the sales force. Sales orientation and market orientation influence customer orientation. In addition, sales orientation, market orientation, and customer orientation influence sales consulting. Sales orientation can increase if coupled with the ability of salespeople to carry out their duties, always paying attention to customer satisfaction. Implications of research results thus we need salespeople who have high innovation and creativity to respond to the needs of a very dynamic market. Business management especially in micro and small businesses must pay attention to the needs and desires of customers and fulfill them (customer orientation), and also provide solutions to problems faced by customers.
\end{abstract}

Keywords: customer orientation; market orientation; salesperson performance; selling orientation 


\begin{abstract}
Abstrak: Tujuan penulisan ini untuk menganalisis pengaruh dan hubungan antar variabel yang dapat meningkatkan kinerja konsultan penjualan. Untuk itu pemahaman tentang kebutuhan dan keinginan pelanggan merupakan sesuatu yang mendesak bagi keberhasilan dalam suatu organisasi. Suatu organisasi yang dapat memahami dengan baik selera pelanggan dapat berpengaruh langsung maupun tidak langsung terhadap kinerja tenaga penjualan. Mengingat selera pelanggan yang sangat dinamis dan tingkat variasi yang tinggi, maka tenaga penjual perlu diberdayakan, karena tenaga penjual berfungsi sebagai ujung tombak suatu organisasi dan yang berhadapan langsung dengan pelanggan. Melalui pelatihan termasuk di sini yaitu berbagi pengalaman dengan teman sejawat terutama tenaga penjual yang dianggap berprestasi. Metoda penelitian ini menggunakan sampel 150 tenaga penjual yang melakukan tugas pokok menjual. Purposive sampling digunakan untuk teknik pengambilan sampel. Data yang telah terkumpul dilakukan screening dan trimming data. Uji validitas dan reliabilitas dilakukan untuk menguji kesahihan dan konsistensi jawaban responden. Amos digunakan untuk menganalisis data setelah uji model dilakukan. Hasil penelitian menunjukkan bahwa, orientasi pasar, penjualan adaptasi, dan mengembangkan orientasi pelanggan berpengaruh positif signifikan terhadap kinerja konsultan penjual. Variabel orientasi pelanggan paling berpengaruh terhadap kinerja tenaga penjualan. Orientasi penjualan dan orientasi pasar berpengaruh terhadap orientasi pelanggan. Selain itu orientasi penjualan, orientasi pasar, dan orientasi pelanggan berpengaruh terhadap konsultasi penjualan. Orientasi penjualan dapat meningkat jika disertai dengan kemampuan tenaga penjual dalam melaksanakan tugasnya selalu memerhatikan kepuasan pelanggan. Dengan demikian diperlukan tenaga penjual yang memiliki inovasi dan kreativitas tinggi untuk merespon kebutuhan pasar yang sangat dinamis. Pengelala usaha khususnya pada Usaha Mikro, Kecil, dan Menengah (UMKM) wajib memerhatikan kebutuhan dan keinginan pelanggan dan memenuhinya (orientasi pelanggan). Dapat memberikan solusi atas masalah yang dihadapi pelanggan.
\end{abstract}

Kata kunci: kinerja konsultan penjualan; orientasi pasar; orientasi pelanggan; orientasi penjualan.

\title{
1 PENDAHULUAN
}

Banyak perusahaan belum sadar betapa pentingnya untuk berorientasi pada pasar. Hal ini dapat dilihat dari sulitnya mencari literatur yang membahas tentang perusahaan yang berorientasi pasar yang berdampak pada kinerja penjualan (Zhang \& Walton, 2017). Keterbatasan lain dari sebagian besar studi penelitian orientasi pasar adalah penelitian sebelumnya cenderung fokus pada level unit bisnis strategis, meskipun pada akhirnya harus diimplementasikan di tingkat individu (Ferdinand \& Wahyuningsih, 2018).

Orientasi pasar dipandang penting sebagai faktor yang memengaruhi kinerja perusahaan (Mostert, Styen, \& Mentz, 2017). Dalam orientasi pasar produsen akan mengetahui keinginan pelanggan, pesaing terkait produk yang diciptakan dan keterkaitan antar fungsi dalam industri. Orientasi pasar adalah budaya organisasi yang paling efektif untuk menciptakan perilaku penting dalam penciptaan nilai unggul bagi pembeli dan kinerja dalam bisnis (Dursun, 2015). Orientasi pasar merupakan suatu proses dan aktivitas yang berhubungan dengan penciptaan dan pemuasan pelanggan dengan cara terus menilai kebutuhan dan keinginan pelanggan secara berkesinambungan (Racela \& Thoumrungroje, 2014). Jika produsen ingin melakukan proses inovasi produk, maka keadaan pasar harus diperhatikan, untuk mengetahui bagaimana karakteristik pelanggan dan pesaing. Peran ini banyak dimainkan oleh konsultan penjualan.

Konsultan penjualan selalu berupaya untuk meningkatkan jumlah produk yang terjual (Shoemaker \& Pelham, 2013). Konsultan penjualan selain berusaha mengungkap pelanggan laten tetapi juga mengoptimalkan penjualan secara tradisional. Adapun ciri penjualan tradisonal yaitu hanya mengungkap kebutuhan eksplisit yang dinyatakan oleh pembeli saat berinteraksi dengan tenaga penjual. Banyak pelanggan tidak memiliki pemahaman yang jelas tentang kebutuhan yang dirasakannya (Chakrabarty, Brown, \& Widing, 2013). 
Sebagai tenaga penjualan yang terlibat dalam mendengarkan secara aktif, tenaga penjualan itu memiliki kemampuan yang lebih besar untuk memahami set unik kebutuhan dan masalah pelanggan, yang bisa menyebabkan perilaku penjualan adaptif (Singh \& Das, 2013; Wang, Wang, \& Hou, 2016). Informasi yang dikumpulkan dapat menyebabkan wiraniaga untuk meningkatkan perilaku berorientasi pelanggan yang dirancang untuk memenuhi kebutuhan mereka dengan lebih baik memahami kebutuhan dan masalah. Berdasarkan latar belakang dan fenomena bisnis, penelitian ini bertujuan untuk menganalisis, mengevaluasi, dan mengetahui hubungan serta pengaruh antar variabel penelitian baik secara parsial maupun secara simultan.

Selama ini yang terjadi pada Usaha Mikro, Kecil, dan Menengah (UMKM) yaitu terlalu sibuk dengan kemampuan yang dimiliki, tanpa banyak belajar dari keluhan pelanggan. Seharusnya para pelaku UMKM selain mengembangkan dan menjaga kualitas atas barang yang diproduksinya, tetapi juga memerhatikan kebutuhan dan keinginan pelanggan. Dengan demikian pelaku UMKM harus memiliki antara lain kemampuan beradaptasi, berorientasi pada pelanggan, dan orientasi pasar yang semuanya ini diharapkan dapat meningkatkan penjualan.

Rumusan masalah pada penelitian ini adalah bagaimanakah pengaruh penjualan adaptif terhadap orientasi pasar dan orientasi pelanggan kaitannya dengan peningkatan kinerja konsultan penjualan pada usaha Mikro, Kecil, dan Menengah? Sedangkan tujuan penelitiannya untuk mengkaji dan menganalisis esensi dan peran secara langsung yang berkaitan dengan pengaruh tingkat penjualan adaptif terhadap orientasi pasar dan orientasi pelanggan yang dapat meningkatkan kinerja konsultan penjualan pada Usaha Mikro, Kecil, dan Menengah.

Teori penjualan adaptif pada awalnya diperbincangkan oleh Spiro \& Weits (1990). Tiga aspek penting dalam penjualan adaptif yang harus dilakukan oleh seorang tenaga penjual. Ketiga aspek tersebut yaitu motivasi dari seorang tenaga penjual untuk mempraktikkan konsep adaptive selling. Kedua kemampuan yang dibutuhkan untuk oleh seorang tenaga penjual untuk mempraktikkan penjualan adaptif agar dapat terlaksana secara efektif, dan yang ketiga kemampuan tenaga penjual untuk menerapkannya di lapangan secara nyata. Selain itu kemampuan tenaga penjual memantau dan mengikuti perkembangan di lapangan. Dalam hal ini dibutuhkan kemampuan tenaga penjual untuk memantau bagaimana perilaku individu dalam berinteraksi dan mengubah taktik penjualan. Taktik penjualan perlu dilakukan karena tiap pelanggan memiliki keunikan masing-masing (Wang et al., 2016).

Penelitian sebelumnya menunjukkan bahwa tenaga penjual yang pandai beradaptasi dengan pelanggan, selain dapat memuaskan pelanggan tetapi juga dapat meningkatkan kinerja penjualan (Singh \& Das, 2013). Tenaga penjual yang memiliki motivasi yang kuat untuk berprestasi dan terampil beradaptasi saat berinteraksi dengan pelanggan selain berdampak jangka pendek yaitu dapat mengatasi kesulitan pelanggan dan juga berdampak jangka panjang yaitu dapat meningkatkan kinerja penjualan (Maroofi, Sadegh, Sadegh, \& Fathi, 2011).

Orientasi pasar merupakan bagian dari konsep pasar (Hassan, Qureshi, Hasnain, Sharif, \& Hassan, 2013). Konsep pemasaran menyatakan bahwa keberhasilan suatu organisasi ditentukan oleh kemampuan pemasar untuk memahami dan memenuhi kebutuhan dan keinginan konsumen (Burdenski, 2013). Fokus pelanggan, fokus pesaing, dan koordinasi antar fungsi merupakan tiga dimensi dari orientasi pasar (Chelliah, Kwon, Annamalah, \& Munusamy, 2013). Fokus pelanggan dapat dilakukan dengan selalu memerhatikan keluhan dan menberikan solusi atas masalah yang dihadapi pelanggan. Fokus pesaing dapat dilakukan memerhatikan pesaing dengan cara mencari informasi tentang pesaing. Apa yang pesaing sedang lakukan, kemudian dianalisis dalam organisasi untuk membuat kebijakan perusahaan. Koordinasi antar fungsi dimaksudkan untuk koordinasi antar departemen untuk membuat strategi dan taktik untuk memenangkan persaingan.

Konsep orientasi pelanggan merupakan penerapan dari konsep pemasaran pada tingkat tenaga penjualan (Pousa \& Mathieu, 2013). Tenaga penjual berusaha untuk membantu pelanggan untuk mengatasi kesulitannya, memberikan alternatif produk yang cocok untuk memenuhi kebutuhan sehingga pelanggan merasa puas. Kepuasan pelanggan dapat dilakukan dengan presentasi yang 
menarik bagi pelanggan. Dalam hal ini, tenaga penjual berorientasi jangka pendek untuk mencapai tujuannya melalui kepuasan pelanggan.

Penelitian sebelumnya menunjukkan bahwa pentingnya menjaga kualitas hubungan dengan pelanggan. Kualitas hubungan yang baik dapat diukur dari tingkat retensi pelanggan. Pelanggan dapat dipertahankan jika pelanggan tersebut percaya dengan kinerja tenaga penjual. Untuk mewujudkan kinerja yang baik, tenaga penjual harus dapat memberikan kepuasan maksimal kepada pelanggan, dengan demikian pelanggan tidak mudah beralih ke produk pesaing (Hassan et al., 2013).

Tidak banyak peneliti melakukan penelitian tentang perilaku konsultan penjualan yang berdampak pada pertumbuhan laba perusahaan (Pelham, 2009). Tenaga konsultan penjualan perlu diberikan ketrampilan yang memadai. Agar mendapatkan hasil yang optimal, diperlukan persyaratan yang ketat untuk menjadi seorang konsultan penjualan. Selain itu konsultan penjualan perlu diberikan teknik mendiagnosis pelanggan, keterampilan mendengarkan, dan keterampilan bertanya. Dengan demikian dibutuhkan kemauan belajar bagi konsultan penjualan untuk dapat meningkatkan kompetensi.

\subsection{Penjualan adaptif dan orientasi pasar}

Kemampuan tenaga penjual untuk beradaptasi saat berinteraksi dengan pelanggan sangat diperlukan (Udayana, Farida, \& Ardyan, 2019). Kompetensi ini mendesak bagi tenaga penjual agar dapat memberikan layanan yang dapat memuaskan pelanggan (Zhang \& Walton, 2017). Pelanggan yang merasa mendapatkan apa yang diinginkan sangat mungkin untuk melakukan pembelian ulang. Selain itu mereka secara sukarela akan mendorong teman-temanya untuk membeli produk yang sama yang mereka beli. Dengan demikian fleksibilitas seorang tenaga penjual juga menentukan keberhasilan untuk memberikan layanan kepada pelanggan. Fleksibelitas penjualan sangat dibutuhkan karena tiaptiap pelanggan memiliki keunikan sendiri-sendiri (Wang et al., 2016). Kemampuan ini sangat dibutuhkan untuk lebih dapat memberikan kontribusi yang signifikan terhadap kinerja penjualan.

Keunikan tiap pelanggan harus dapat dipahami dengan baik oleh tenaga penjual (Wang et al., 2016). Kebehasilan tenaga penjual untuk dapat memahami keunikan pelanggan dapat diukur dari jarang ada keluhan dari pelanggan. Pelanggan yang mendapatkan apa yang dibutuhkan dan apa yang diinginkan biasanya mengatakan hal-hal positif tentang suatu produk. Selain itu pelanggan tersebut juga merekomendasikan dengan sukarela kepada koleganya tentan manfaat suatu produk. Dengan demikian hipotesis yang diusulkan:

\section{H1 Penjualan adaptif berpengaruh positif signifikan terhadap orientasi pasar}

\subsection{Penjualan adaptif dan orientasi pelanggan}

Gemar bereksperimen merupakan salah satu kompetensi yang harus dimiliki oleh seorang tenaga penjual (Bande \& Ferrín, 2015). Hal ini perlu untuk lebih memberikan makna kebutuhan yang dirasakan pelanggan. Pelanggan yang kebutuhannya telah dipenuhi akan merasa puas (Poot, Wopereis, Elzen, Gussekloo, \& Bloom, 2019; Udayana et al., 2019). Kepuasan adalah aset utama bagi perusahaan untuk dapat lebih berkembang untuk memberikan layanan terbaik kepada pelanggan. Melalui eksperimen seorang tenaga penjual akan mendapatkan banyak pengalaman yang mungkin tidak terpikirkan sebelumnya. Mungkin ada pelanggan yang mengedepankan persaudaraan jadi tidak hanya terbatas hanya sekedar hubungan jual beli semata.

Persaudaraan dengan pelanggan perlu dibina agar semakin erat. Persaudaraan akan dapat berjalan dengan baik jika dibarengi oleh tenaga penjual yang memiliki kemampuan beradaptasi yang baik saat berinteraksi dengan pelanggan (Maroofi et al., 2011). Dengan demikian keterampilan dan kecerdasan tenaga penjual perlu ditingkatkan secara sistemik dan terstruktur. Hal ini dapat dilakukan melalui pelatihan-pelatihan secara teratur dan mengikuti perkembangan selera pelanggan yang cenderung dinamis. Dengan demikian hipotesis yang diusulkan:

H2 Penjualan adaptif berpengaruh positif signifikan terhadap orientasi pelanggan 


\subsection{Orientasi pasar dan kinerja konsultan penjualan}

Kemampuan tenaga penjual untuk menciptakan dan mengantarkan nilai tambah kepada pelanggan merupakan langkah strategis untuk memermudah pelanggan dalam penggunaan produk (Paramita, Zheng, Haque, Washington, \& Hyland, 2018; Poot et al., 2019). Semakin banyak nilai tambah yang dapat diciptakan oleh tenaga penjual maka pelanggan semakin banyak mendapatkan kemudahan dan kepraktisan dalam konsumsi suatu produk. Dengan sendirinya masalah yang dihadapi pelanggan akan semakin dapat teratasi. Dengan demikian konsumen merasa puas. Perasaan puas ini dapat melahirkan rekomendasi ke pelanggan potensial untuk melakukan hal yang sama yaitu kesediaan dan dengan sukarela untuk membeli suatu produk (Napitupulu \& Okky, 2014). Penting sekali memelihara kepuasan yang sudah dirasakan oleh pelanggan. Bentuk yang dapat dilakukan dengan selalu mencari solusi atas masalah yang dihadapi pelanggan.

Kepuasan pelanggan dapat terjaga dengan baik jika diikuti oleh kecepatan dalam merespon keluhan pelanggan dan memberikan solusi atas masalah yang dihadapi pelanggan (Chu \& Yuan, 2012). Kecepatan respon pelanggan misalnya dapat dilakukan dengan cara layanan bebas pulsa dan layanan sepanjang hari atau dupuluh empat jam nonstop. Pelanggan yang mengadukan keluhannya dapat secara cepat dan tanpa dibebani biaya komunikasi. Dengan demikian hipotesis yang dapat diusulkan:

H3 Orientasi pasar berpengaruh positif terhadap kinerja konsultan penjualan

\subsection{Penjualan adaptif dan kinerja konsultan penjualan}

Kemampuan tenaga penjual untuk menguasai berbagai pendekatan dalam penjualan sangatlah penting (Maroofi et al., 2011; Singh \& Das, 2011). Tenaga penjual harus memiliki tipe layanan yang berbeda bagi setiap pelanggan. Hal ini dimungkinkan karena pelanggan sangat beraneka ragam baik dari sisi pendidikan, latar belakang, pengalaman bertransaksi, dan usia pelanggan, serta tingkat kecerdasan pelanggan. Dengan demikian tenaga penjual harus selalu meng-update pengetahuannya demi dapat mengimbangi pelanggan yang selalu dinamis baik kebutuhannya maupun seleranya. Selalu belajar dari kesalahan dan memerhatikan perkembangan teknologi terbaru adalah suatu hal yang mutlak harus dilakukan oleh pelanggan (Dulger, Alpay, Yilmaz, \& Bodur, 2016; Vij \& Farooq, 2015). Jika hal ini dapat dilakukan dengan baik, maka tenaga penjual tersebut dapat memenangkan persaingan yang semakin ketat.

Pendekatan yang berbeda diperlukan untuk pelanggan yang berbeda. Hal ini dikarenakan pelanggan memiliki karakter yang berbeda satu sama lain. Jika hal ini dapat dipahami dengan baik oleh tenaga penjual, maka hal ini dapat meningkatkan kinerja konsultan penjualan. Konsultan penjualan dapat membantu tenaga penjual untuk memantapkan tujuan yang telah ditetapkan. Karena untuk mencapai tujuan, perlu sterategi serta taktik yang tepat (Gomes, Yasin, \& Small, 2016). Dengan demikian hipotesis yang diusulkan:

H4 Penjualan adaptif berpengaruh positif signifikan terhadap kinerja konsultan penjualan.

\subsection{Orientasi pelanggan dan kinerja konsultan penjualan}

Mengukur kepuasan pelanggan secara periodik merupakan langkah strategis untuk meminalisir keluhan yang dilakukan pelanggan (Locander, Weinberg, \& Locander, 2018; Mostert et al., 2017). Pengukuran ini penting sebagai antisipasi dini untuk layanan yang terbaik dengan pelanggan. Dengan memerhatikan unsur-unsur penting bagi pelanggan tentunya hal ini berdasarkan hasil dari survei tentang kepuasan pelanggan. Dengan memerhatikan hal-hal penting tersebut dapat dipakai sebagai pedoman untuk dapat memberikan layanan terbaik bagi pelanggan. Kecepatan memberikan tanggapan atas keluhan pelanggan juga sangat menentukan keberhasilan kinerja konsultan penjualan (Gupta, 
2016; Tawinunt, Phimonsathien, \& Fongsuwan, 2015). Pelanggan yang mendapatkan layanan yang cepat dan akurat, pelanggan dapat merasa puas.

Untuk mengukur kepusan pelanggan dapat dilakukan dengan survei kepuasan nasabah atas layanan yang telah diterima selama ini. Melalui pengisian kuesioner yang diterima pelanggan mengisi setiap pertanyaan yang sesuai dengan apa yang dialami selama menggunakan produk yang dibeli. Dengan demikian hipotesis yang diusulkan sebagai berikut:

H5 Orientasi pelanggan berpengaruh positif terhadap kinerja konsultan penjualan

\section{METODE}

Populasi penelitian ini yaitu para UMKM di wilayah Yogyakarta. Sampel penelitian sejumlah 250 responden. Teknik pengambilan sampelnya yaitu purposive sampling. Adapun unit analisisnya adalah pelaku UMKM yang melakukan tugas pokok penjualan produk UMKM. Data dikumpulkan dengan menggunakan kuesioner yang telah diuji validitas dan reliabilitasnya terlebih dahulu. Skala pengukuran dengan menggunakan skala ordinal.

Penelitian ini menggunakan empat variabel yakni penjualan adaptif, orientasi pasar, orientasi pelanggan, dan kinerja konsultan penjualan. Definisi operasional dan pengukuran variabel yang dipakai dalam analisis model dapat dijelaskan pada Tabel 1.

Tabel 1. Definisi operasional, dimensi, dan indikator penelitian

\begin{tabular}{|c|c|c|c|c|c|}
\hline Variabel & Definisi & Dimensi & Indikator & Skala & Sumber \\
\hline $\begin{array}{l}\text { Penjualan } \\
\text { adaptif }\end{array}$ & 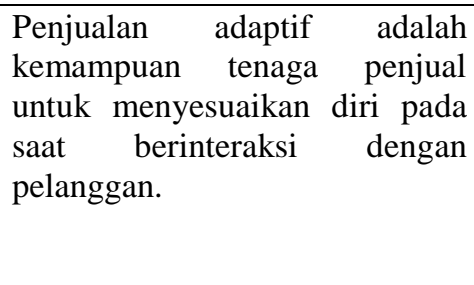 & $\begin{array}{l}\text { Pendekatan, } \\
\text { Presentasi, } \\
\text { Teknis. }\end{array}$ & $\begin{array}{l}\text { Pendekatan } \\
\text { penjualan, materi } \\
\text { presentasi } \\
\text { penjualan, teknis } \\
\text { penjualan }\end{array}$ & $\begin{array}{l}\text { Ordinal, } \\
\text { dengan } \\
\text { 7-point } \\
\text { skala } \\
\text { likert, } \\
\text { 1=STS } \\
\text { s/d } 7 \text { SS }\end{array}$ & $\begin{array}{l}\text { (Chena \& } \\
\text { Jaramillob, } \\
\text { 2014) }\end{array}$ \\
\hline $\begin{array}{l}\text { Orientasi } \\
\text { pasar }\end{array}$ & $\begin{array}{l}\text { Orientasi pasar } r \text { adalah } \\
\text { kemampuan tenaga penjual } \\
\text { untuk memahami dinamika } \\
\text { pasar dan selera pasar. }\end{array}$ & $\begin{array}{l}\text { Kebutuhan, } \\
\text { Keinginan, } \\
\text { Solusi. }\end{array}$ & $\begin{array}{l}\text { Kebutuhan } \\
\text { pelanggan, } \\
\text { keinginan } \\
\text { pelanggan, } \\
\text { problem solving }\end{array}$ & $\begin{array}{l}\text { Ordinal, } \\
\text { dengan } \\
\text { 7-point } \\
\text { skala } \\
\text { likert, } \\
\text { 1=STS } \\
\text { s/d } 7 \text { SS }\end{array}$ & $\begin{array}{l}\text { (Abiodun \& } \\
\text { Mahmood, } \\
\text { 2015; } \\
\text { Dursun, } \\
\text { 2015) }\end{array}$ \\
\hline $\begin{array}{l}\text { Orientasi } \\
\text { pelanggan }\end{array}$ & $\begin{array}{l}\text { Orientasi pelanggan adalah } \\
\text { kemampuan tenaga penjual } \\
\text { untuk menciptakan nilai tambah } \\
\text { yang bermanfaat bagi } \\
\text { pelanggan. }\end{array}$ & $\begin{array}{l}\text { Value, } \\
\text { Satisfaction, } \\
\text { Respon. }\end{array}$ & $\begin{array}{l}\text { Penciptaan nilai } \\
\text { pelanggan, } \\
\text { kepuasan } \\
\text { pelanggan, } \\
\text { kecepatan respon. }\end{array}$ & $\begin{array}{l}\text { Ordinal, } \\
\text { dengan } \\
\text { 7-point } \\
\text { skala } \\
\text { likert, } \\
\text { 1=STS } \\
\text { s/d } 7 \text { SS }\end{array}$ & $\begin{array}{l}\text { (Singh \& } \\
\text { Das, 2013) }\end{array}$ \\
\hline $\begin{array}{l}\text { Kinerja } \\
\text { konsultan } \\
\text { penjualan }\end{array}$ & $\begin{array}{l}\text { Kinerja konsultan penjualan } \\
\text { adalah kemampuan tenaga } \\
\text { penjual untuk memberikan } \\
\text { motivasi dan solusi atas masalah } \\
\text { yang dihadapi pelanggan. }\end{array}$ & $\begin{array}{l}\text { Konsultasi, } \\
\text { Tujuan, } \\
\text { Alternatif } \\
\text { souusi. }\end{array}$ & $\begin{array}{l}\text { Kesempatan } \\
\text { konsultasi } \\
\text { penjualan, } \\
\text { pemantapan } \\
\text { tujuan, mencari } \\
\text { alternatif solusi. }\end{array}$ & $\begin{array}{l}\text { Ordinal, } \\
\text { dengan } \\
\text { 7-point } \\
\text { skala } \\
\text { likert, } \\
\text { 1=STS } \\
\text { s/d } 7 \text { SS }\end{array}$ & $\begin{array}{l}\text { (Williams, } \\
\text { 2000) }\end{array}$ \\
\hline
\end{tabular}

Sumber: Pengolahan data sekunder (2018)

Uji validitas dan reliabilitas dilakukan sebelum data diolah lebih lanjut. Uji kelayakan model dilakukan dengan memerhatikan cut of point sesuai yang disyaratkan dalam uji structural Equation model (SEM) (Ferdinand, 2006; Ghozali, 2011). Uji kelayakan model dilakukan dengan memerhatikan 
nilai-nilai antara lain: chi-square, gfi, agfi, tli, cfi, rmsea, cmindf, dan nfi. Setelah model layak, dilanjutkan dengan analisis data dengan menggunakan AMOS v. 24.

Berdasarkan uraian dan analisis dari temuan-temuan penelitian sebelumnya serta saling keterkaitan antar variabel, dapat dibuat sebuah model penelitian empiris seperti disajikan dalam Gambar 1.

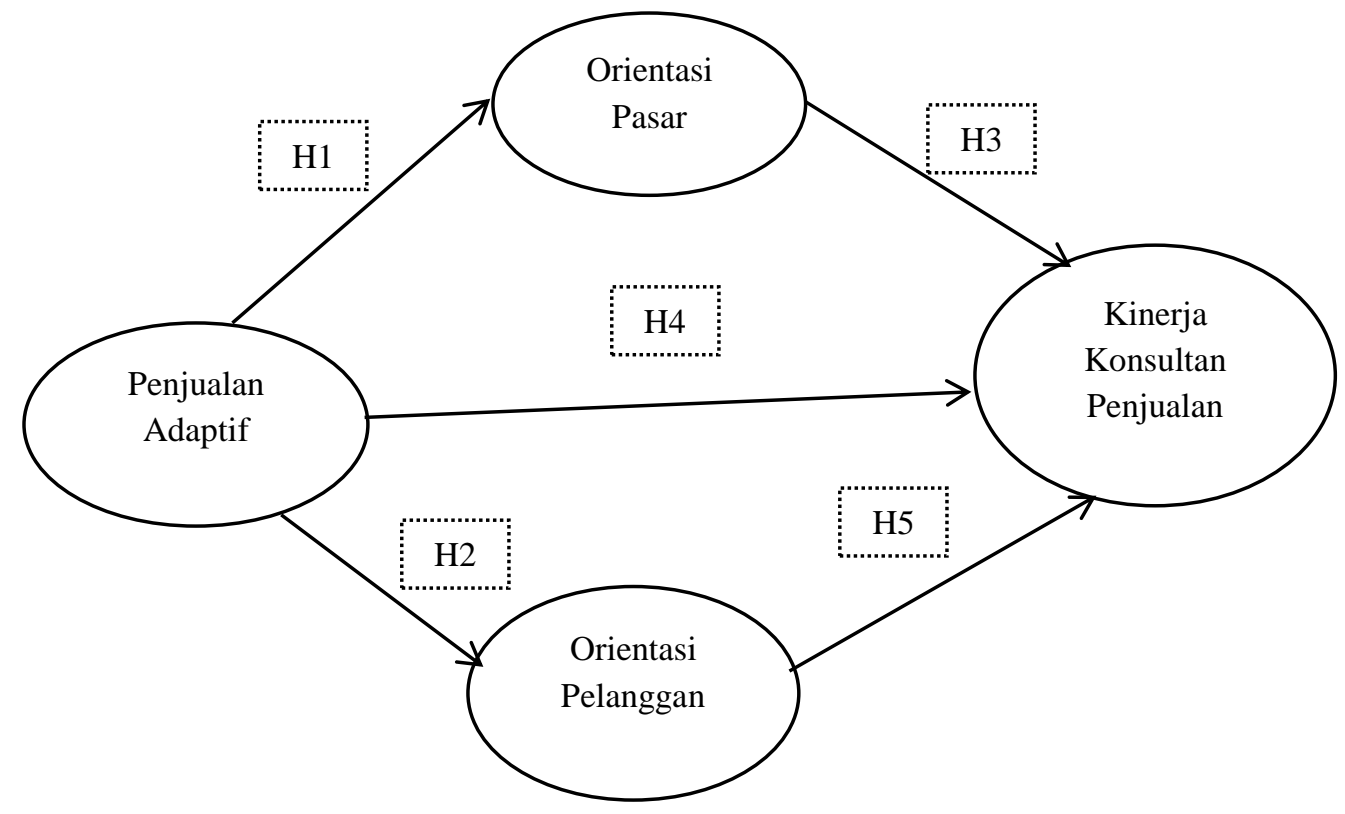

Gambar 1. Model penelitian empiris

Sumber: Pelham (2009)

\section{HASIL DAN PEMBAHASAN}

Peneliti melakukan confirmatory factor analysis untuk mendapatkan pengukuran yang akurat sebelum melakukan estimasi terhadap model struktural (Hair, Black, Babin, \& Anderson, 2010). Indikator yang memiliki loading factor di bawah 0.50 di-drop. Model secarata statistik dinyatakan fit dan dapat diterima dengan nilai $\chi 2=158.483, \mathrm{df}=99, \mathrm{p}<0.000 ; \mathrm{RMSEA}=0.058 ; \mathrm{CFI}=0.980 ;$ AGFI $=0.871$; $\mathrm{GFI}=0.906 ; \mathrm{NFI}=0.948$. Sementara $\chi^{2}$ keseluruhan signifikan, $\chi 2$ yang/rasio df (1.601).

Selanjutnya peneliti menilai convergen dan discriminan validity. Convergen maupun internal validity mengukur item-item benar-benar mengukur konstruk yang secara teoritis seharusnya diukur. Hal ini dicapai melalui analisis reliabilitas, setiap konstruk memiliki cronbach alpha di atas 0.75 (Hair et al., 2010). Seluruh konstruk dengan loading factor, coefisien alpha, dan avarage variance extracted (AVE) disajikan pada Tabel 2.

Tabel 2. Scale item with loading factor and reliabilities

\begin{tabular}{|c|c|c|}
\hline & $\begin{array}{l}\text { Coefficient } \\
\text { alpha }\end{array}$ & $\begin{array}{l}\text { Standardized } \\
\text { loading }\end{array}$ \\
\hline Penjualan adaptif (Maroofi et al., 2011) AVE $=0.552$. & 0.93 & \\
\hline $\begin{array}{l}\text { Ketika saya merasa pendekatan saya tidak jalan, maka saya dengan } \\
\text { mudah mengubah dengan pendekatan yang lain. }\end{array}$ & & 0.774 \\
\hline Saya menggunakan pendekatan berbeda untuk pelanggan yang berbeda. & & 0.804 \\
\hline Saya dapat dengan mudah mengatasi kesulitan pelanggan. & & 0.802 \\
\hline Saya selalu mudah untuk beradaptasi dengan beberapa pelanggan. & & 0.602 \\
\hline Orientasi pelanggan (Paschal \& Eid, 2011), AVE $=0.52$ & 0.93 & \\
\hline Saya menekankan makna kepuasan bagi konsumen. & & 0.909 \\
\hline
\end{tabular}




\begin{tabular}{|c|c|c|}
\hline & $\begin{array}{l}\text { Coefficient } \\
\text { alpha }\end{array}$ & $\begin{array}{l}\text { Standardized } \\
\text { loading }\end{array}$ \\
\hline Saya menekankan makna dari kebutuhan pelanggan. & & 0.933 \\
\hline Saya mengukur kepuasan pelanggan secara berkala. & & 0.925 \\
\hline Saya selalu merespon dengan cepat keluhan pelanggan & & 0.924 \\
\hline Kinerja konsultan penjualan (Abed \& Haghighi, 2009) AVE $=0.58$ & 0.92 & \\
\hline $\begin{array}{l}\text { Saya menghabiskan banyak waktu membantu pelanggan saya } \\
\text { mendiagnosis akar penyebab masalah pelanggan. }\end{array}$ & & 0.933 \\
\hline $\begin{array}{l}\text { Saya menghabiskan sangat banyak waktu bekerja dengan pelanggan saya } \\
\text { untuk membantu menyelesaikan masalah atau membantu memantapkan } \\
\text { tujuan mereka. }\end{array}$ & & 0.954 \\
\hline $\begin{array}{l}\text { Saya menghabiskan banyak waktu untuk bekerja dengan fungsi-fungsi } \\
\text { lain di perusahaan saya untuk mencari solusi untuk masalah pelanggan } \\
\text { saya. }\end{array}$ & & 0.925 \\
\hline $\begin{array}{l}\text { Dibandingkan dengan tenaga penjualan lainnya di perusahaan kami, saya } \\
\text { menghabiskan lebih banyak waktu untuk memecahkan masalah } \\
\text { pelanggan saya daripada membuat presentasi penjualan. }\end{array}$ & & 0.924 \\
\hline Orientasi pasar (Paschal \& Eid, 2011), AVE $=0.52$ & 0.93 & \\
\hline $\begin{array}{l}\text { Semua tenaga penjualan kami memahami bagaimana seluruhnya dapat } \\
\text { berkontribusi untuk menciptakan/ mendapatkan pelanggan. }\end{array}$ & & 0.909 \\
\hline $\begin{array}{l}\text { Perusahaan kami merespons dengan cepat terhadap informasi kepuasan } \\
\text { pelanggan. }\end{array}$ & & 0.877 \\
\hline $\begin{array}{l}\text { Strategi perusahaan kami banyak didorong oleh pemahaman kami } \\
\text { tentang kemungkinan untuk menciptakan nilai tambah bagi pelanggan. }\end{array}$ & & 0.920 \\
\hline $\begin{array}{l}\text { Strategi perusahan kami untuk keunggulan kompotitif didasarkan pada } \\
\text { pemahaman menyeluruh kami terhadap kebutuhan pelanggan. }\end{array}$ & & 0.945 \\
\hline
\end{tabular}

Sumber: Hasil pengolahan Amos (2018)

Analisis model struktural dilakukan setelah dilakukan analisis faktor konfirmatori dan memastikan bahwa model konfirmatori valid dan reliabel untuk masing-masing variabel. Hasil analisis untuk full model persamaan struktural terlihat pada Gambar 2.

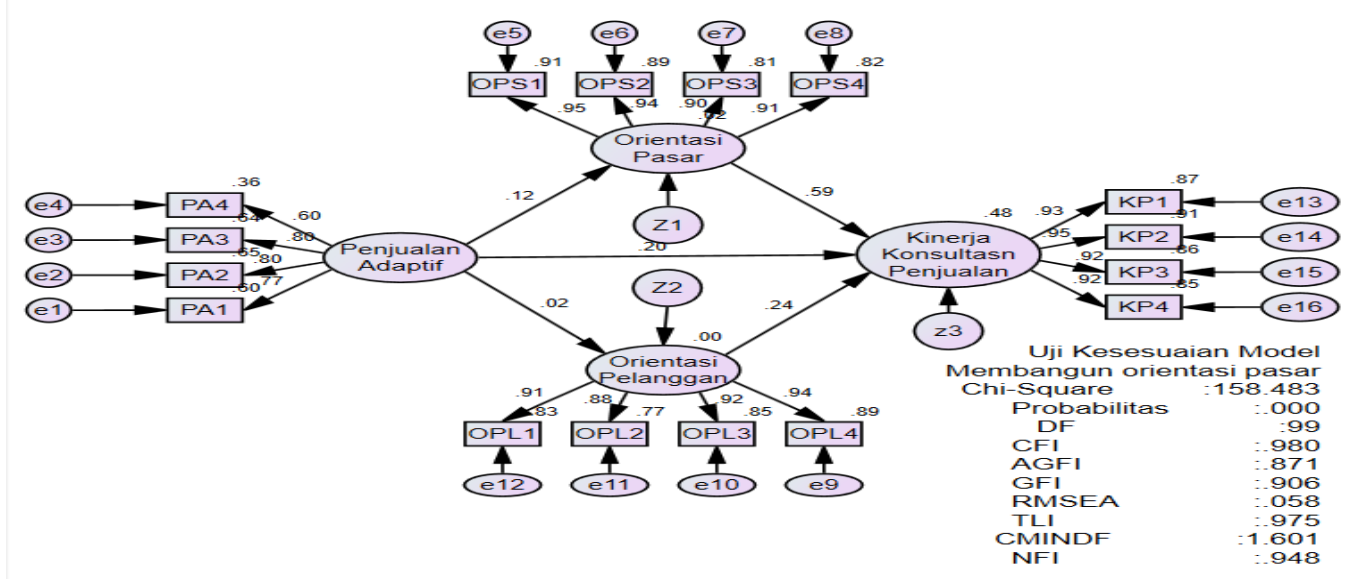

Gambar 2. Analisis model persamaan struktural

Sumber: Pengolahan data primer (2018)

Gambar 2 menjelaskan bahwa penjualan adaptif dan orientasi pelanggan tidak berpengaruh positif signifikan terhadap kinerja konsultan penjualan, namun orientasi pelanggan dan orientasi pasar tidak dipengaruhi oleh penjualan adaptif. Dua hipotesis ditolak dan tiga hipotesis diterima. Hipotesis 1 hubungan yang tidak signifikan antara orientasi penjualan dan orientasi pasar $(\mathrm{H} 1: \beta=0.12, p<$ 
0.141). Hubungan yang tidak signifikan antara orientasi penjualan dengan orientasi pelanggan $(\mathrm{H} 2$ : $\beta$ $=0.024, \mathrm{p}<0.776)$. Hubungan positif signifikan antara orientasi pasar terhadap konsultan penjualan $(\mathrm{H} 3: \beta=0.630 \mathrm{p}<0.000)$, hubungan positif signifikan signifikan orientasi penjualan dengan konsultan penjualan (H4: $\beta=0.216, \mathrm{p}=<0.000)$ dan hipotesis 5 ada pengaruh positif signifikan antara orientasi pelanggan dengan kinerja konsultan penjualan $(\mathrm{H} 5: \beta=0.235, \mathrm{p}<0.000)$.

Tabel 3 Hasil uji hipotesis, seluruh standardize regresi coefficient, dan probabilitas

\begin{tabular}{|c|c|c|c|c|c|}
\hline \multicolumn{4}{|c|}{ Relationships } & \multirow{2}{*}{$\begin{array}{l}\text { Estimasi } \\
0.12 \text { (ns) }\end{array}$} & \multirow{2}{*}{$\begin{array}{l}\text { Prob. } \\
0.141\end{array}$} \\
\hline H1 & Penjualan adaptif & $\rightarrow$ & Orientasi pasar & & \\
\hline $\mathrm{H} 2$ & Penjualan adaptif & $\rightarrow$ & Orientasi pelanggan & $0.024(\mathrm{~ns})$ & 0.776 \\
\hline H3 & Orientasi pasar & $\rightarrow$ & Kinerja konsultan penjualan & $0.630 * * *$ & 0.000 \\
\hline $\mathrm{H} 4$ & Penjualan adaptif & $\rightarrow$ & Kinerja konsultan penjualan & $0.216 * *$ & 0.000 \\
\hline H5 & Orientasi pelanggan & $\rightarrow$ & Kinerja konsultan penjualan & $0.235^{* * *}$ & 0.000 \\
\hline
\end{tabular}
$N=160 ; * p<.05, * * p<.01, p<.001$.

Sumber: Pengolahan data primer (2018)

Variabel orientasi pasar merupakan variabel yang paling berpengaruh terhadap kinerja konsultan penjualan. Kemudian berturut-turut orientasi pelanggan, lalu adaptive selling. Namun peran orientasi pasar dan orientasi pelanggan belum mampu menjadi variabel intervening. Variabel adaptive seling tidak berpengaruh terhadap variabel orientasi pasar dan variabel orientasi pelanggan.

Variabel orientasi pasar perlu dikembangkan lagi untuk meningkatkan kinerja konsultan. Oleh karena itu semua fungsi di perusahaan yang terlibat langsung dengan penjualan harus berkontribusi untuk mendaptkan pelanggan baru. Dengan demikian perlu respon cepat atas masalah pelanggan yang muncul. Selain itu kemampuan tenaga penjual untuk menciptakan nilai tambah yang bermanfaat bagi pelanggan sangat diperlukan (Tawinunt et al., 2015). Mengukur kepuasan pelanggan secara periodik merupakan kegiatan yang harus dilakukan demi terjaganya kualitas layanan yang terbaik bagi pelanggan. Selalin itu kecepatan untuk merespon keluhan pelanggan juga penting dan mendesak harus dilakukan (Chow, 2015).

Variabel penjualan adaptif tidak berpengaruh terhadap orientasi pasar maupun orientasi pelanggan. Tenaga penjual yang memiliki kompetensi untuk beradaptasi saat berinteraksi dengan pelanggan tidak selalu dapat menciptakan kepuasan bagi pelanggan. Hal ini disebabkan oleh kondisi dan situasi bagi pelanggan tertentu. Saat ini banyak pelanggan menghendaki urusan selesai dengan biaya minimal dan tidak perlu banyak basa basi (Toyese, 2014). Mengingat kesibukan yang dialami oleh pelanggan itu sendiri, namun demikian tidak berarti tenaga penjual tidak perlu ramah, tetap diperlukan khususnya pada produk jasa yang membutuhkan penjelasan tentang produk yang dibelinya.

\section{SIMPULAN DAN SARAN}

Berdasarkan uraian pada bagian sebelumnya, dapat disimpulkan bahwa untuk meningkatkan pemahaman tentang kebutuhan dan keinginan pelanggan maka seorang tenaga penjual harus meningkatkan kemampuan dirinya dalam hal adaptasi, saat beradaptasi dan berinteraksi dengan pelanggan. Dengan demikian kompetensi tenaga penjual perlu ditingkatkan khususnya menggunakan pendekatan yang berbeda pada pelanggan yang berbeda karena masing-masing pelanggan memiliki keunikan sendiri-sendiri.

Kemampuan untuk mengatasi kesulitan pelanggan merupakan peran penting yang harus dilakukan oleh seorang tenaga penjual. Jika hal ini dapat dilakukan dengan baik, maka konsumen mendapatkan kepuasan. Agar kepuasan pelanggan dapat terjaga, maka perlu dilakukan pengukuran kepuasan pelanggan secara periodik. Selain itu kecepatan menangani keluhan pelanggan juga menentukan kepuasan pelanggan.

Membantu pelanggan untuk dapat memahami dengan masalah yang dihadapi pelanggan merupakan tugas penting bagi seorang konsultan penjualan. Untuk itu perlu semua yang terlibat dalam penjualan perlu memberikan kontribusi demi terciptanya kepuasan dan untuk mendapatkan pelanggan 
baru. Dengan demikian sangat diperlukan untuk menciptakan nilai tambah yang bermakna bagi pelanggan. Sehingga pelanggan mendapatkan kemudahan dan kepraktisan dalam menggunakan produk yang dibelinya.

Obyek penelitian penelitian dapat diperluas, jadi tidak hanya UMKM di Yogyakarta, namun diperluas sampai ke lima provinsi. Dengan demikian dapat diperoleh data yang lebih akurat dan hasil yang lebih tepat. Penelitian mendatang, variabel dependennya ditambah, jadi tidak hanya tiga variabel, namun ditambah misalnya smart working dan hard working. Penelitian mendatang perlu dilakukan pola penelitian longitudinal. Pada pola penelitian ini data yang diperoleh lebih lengkap dan akurat, karena waktu yang tersedia cukup panjang. Selain itu pola penelitian dyadic perlu dilakukan untuk mendapatkan hasil penelitian dengan akurasi yang tinggi.

Kemampuan responden untuk dalam mengisi kuesioner dan mengembalikan kuesioner perlu ditingkatkan. Hal ini dapat dilihat dari banyak kuesioner yang diisi tidak sempurna dan ada kuesioner yang tidak dikembalikan. Serta tingkat pendidikan rata-rata responden masih rendah, sehingga perlu dibantu dan dipandu dalam pengisian kuesioner. Penelitian ini hanya dilakukan di Daerah Istimewa Yogyakarta. Data yang diperolehpun sangat terbatas baik kuantitas maupun kualitas data. Dari sisi variabel penelitian, terutama variabel independennya perlu diperbanyak. Karena pada kenyataannya banyak faktor yang memengaruhi kinerja konsultan penjualan. Pola penelitian hanya berpola cross section, jadi banyak informasi penting yang seharusnya dapat digali oleh peneliti, tetapi lewat begitu saja, karena singkatnya waktu yang disediakan kepada responden dalam mengisi kuesioner.

Para pelaku UMKM perlu melakukan terobosan-terobosan sebagai upaya untuk meningkatkan penjualan, misalnya memaksimalkan pemasaran online. Hal ini perlu dilakukan karena saat ini tidak efektif hanya mengandalkan pemasaran secara tradisional. Selain itu kemampuan pelaku UMKM untuk lebih menggali informasi, baik informasi dari pelanggan maupun informasi dari pesaing. Informasi tersebut dapat dimanfaatkan untuk menyempurnakan strategi pemasaran yang sudah ada. Informasi dari pesaing bermanfaat untuk penyempurnaan kualitas produk.

\section{REFERENSI}

Abed, G.M. \& Haghighi, M. (2009). The effect of selling strategies on sales performance. Business Strategy Series, 10(5), 266-282. doi: 10.1108/17515630910989169

Abiodun, S.T. \& Mahmood, R. (2015). Fostering export performance in SMEs: The roles of export market orientation and learning orientation in turbulent environment. International Journal of Economic Perspectives, 9(2), 28-48. Diperoleh dari http://www.econ-society.org

Bande, B. \& Ferrín, P.F. (2015). How and when does emotional intelligence influence salesperson adaptive and proactive performance? European Management Review, 12, 261-274. doi: 10.1111/emre. 12062

Burdenski, H.M.S.N.D. (2013). The use of direct marketing by colleges and universities an application ofrapp and collins maximarketing model. Journal of Marketing, 77, 1-14. Diperoleh dari https://doi.org/10.1002/dir.4000050409

Chakrabarty, S., Brown, G., \& Widing II, R.E. (2013). Distinguishing between the roles of customeroriented selling and adaptive selling in managing dysfunctional conflict in buyer-seller relationships. Journal of Personal Selling \& Sales Management, xxxiii(3), 245-260. doi: 10.2753/PSS0885-3134330301

Chelliah, S., Kwon, C.K., Annamalah, S., \& Munusamy, J. (2013). Does marketing mix still relevant? A study on herbal coffee in Malaysia. International Journal of Management and Innovation, 5(1), 31-45. Diperoleh dari https://www.questia.com/library/journal/1G1-347522548/doesmarketing-mix-still-relevant-a-study-on-herbal

Chena, C.C. \& Jaramillob, F. (2014). The double-edged effects of emotional intelligence on the adaptive selling-salesperson-owned loyalty relationship. Journal of Personal Selling \& Sales Management, 34(1), 33-50. doi: 10.1080/08853134.2013.870183

Chow, W. (2015). Investigating customers' satisfaction with brand pages in social networking sites. The Journal of Computer Information Systems, 55(2), 48 - 62. doi: $10.1080 / 08874417.2015 .11645756$

Chu, P.Y. \& Yuan, G. (2012). Service quality, customer satisfaction, customer trust, and loyalty in an e-banking context. Social Behavior and Personality, 40(8). doi: org/10.2224/sbp.2012.40.8.1271 
Dulger, M., Alpay, G., Yilmaz, C., \& Bodur, M. (2016). How does learning orientation generate product innovativeness and superior firm performance? International Journal of Business and Economic Development, 4(2), 68-77. Diperoleh dari www.ijbed.org

Dursun, T. (2015). The effect of market orientation on new product performance: The role of strategic capabilities. International Academy of Marketing Studies Journal, 19(3),169-187. doi: $10.1108 / 14601061211192852$

Ferdinand, A.T. (2006). Structural equation modeling in management research. Semarang: Badan Penerbit Universitas Diponegoro.

Ferdinand, A.T. \& Wahyuningsih, W. (2018). Salespeople's innovativeness: a driver of sales performance. Management \& Marketing Challenges for the Knowledge Society, 13(2), 966984. doi:10.2478/mmkcs-2018-0016

Ghozali, I. (2011). Model persamaan bertingkat konsep dan aplikasi dengan program AMOS 210. Semarang: Badan Penerbit Universitas Diponegoro.

Gomes, C.F., Yasin, M.M., \& Small, M.H. (2016). Capabilities as components of competitive strategy in the Portuguese service sector. Int. J. of Services and Operations Management, 20(3), 302319. Diperoleh dari https://doi.org/10.17559/TV-20150624082830

Gupta, A. (2016). Redefining service quality scale with customer experience quality scale: A critical review. Int. J. of Services and Operations Management, 25 (1), 4864. doi: doi.org/10.1504/IJSOM.2016.078070

Hair, J.F., Black, W.C., Babin, B.J., \& Anderson, R.E. (2010). Multivariate data analysis. Pearson Prentice Hall, Seventh Edition.

Hassan, M.U., Qureshi, S.U., Hasnain, A., Sharif, I., \& Hassan, R. (2013). Market orientation, learning orientation and organizational performance: Evidence from banking industry of Pakistan. Science International Journal, 25 (4), 945-956 Diperoleh dari https://www.researchgate.net/profile/Saif_Qureshi/publication/284283652

Locander, D.A., Weinberg, F.J., \& Locander, W.B. (2018). The mediating role of sales department innovation orientation on creative selling. Journal of Managerial Issues, 30(4), 463-482. Diperoleh dari https://eresources.perpusnas.go.id:2057/login?url=http://search.ebscohost.com/login.aspx?direct=true $\& \mathrm{db}=$ ehh \&AN $=134395527 \&$ site $=$ ehost-live

Maroofi, F., Sadegh, F., Sadegh, G., \& Fathi, D. (2011). Adaptive Selling Behavior In Iran Automobile Sales Representatives. International Journal of Academic Research, 3(2), 225230. Diperoleh https://research.uok.ac.ir/ fmaroofi/en/ViewResearchEn.aspx?ResearcherID=19480

dari

Mostert, P.G., Steyn, T.F.J., \& Mentz, M.H. (2017). Relationship intention and customer satisfaction as predictors of South African SMEs' loyalty towards a risk financier. Journal of Global Business \& Technology, 13(1), 11-24. Diperoleh dari http://search.ebscohost.com/login.aspx?direct=true \&db=egs\&AN=136139792\&site=ehostlive

Napitupulu, T.A. \& Okky, K. (2014). A structural equations modeling of purchasing decision through e-commerce. Journal of Theoretical and Applied Information Technology, 60(2). Diperoleh dari www.jatit.org

Paramita, P., Zheng, Z., Haque, M.M., Washington, S., \& Hyland, P. (2018). User satisfaction with train fares: A comparative analysis in five Australian cities. PLoS ONE, 13(6), 1-26. doi:10.1371/journal.pone.0199449

Paschal, A.U. \& Eid, R. (2011). Integrating internal customer orientation, internal service quality, and customer orientation in the banking sector: An empirical study. The Service Industries Journal, 31(14), 2487-2505. doi: 10.1080/02642069.2010.504822

Pelham, A.M. (2009). An exploratory study of the influence of firm market orientation on salesperson adaptive selling, customer orientation, interpersonal listening in personal selling and salesperson consulting behaviors. Journal of Strategic Marketing, 17(1), 21-39 doi: $10.1080 / 09652540802619202$

Poot, A.J., Wopereis, D.M., den Elzen, W.P.J., Gussekloo, J., \& Blom, J.W. (2019). Changes in patient satisfaction related to their perceived health state during implementation of improved integrated care for older persons. PLoS ONE, 14(5), 1-11. Diperoleh dari http://search.ebscohost.com/login.aspx?direct=true $\& \mathrm{db}=$ agp \&AN=136474964\&site=ehostlive. doi:10.1371/journal.pone.0216028

Pousa, C. \& Mathieu, A. (2013). Boosting customer orientation through coaching: A Canadian study. International Journal of Bank Marketing, 32(1), 60-81. doi: 10.1108/IJBM-04-20130031/full/html

Racela, O.C. \& Thoumrungroje, A. (2014). Export Market orientation, interfirm communication, interfirm cooperation and export performance. Global Conference on Business and Finance Proceedings, 9(1), 244-254. doi: ONLINE \& ISSN 2168-0612 USB Flash Drive 
Shoemaker, M.E. \& Pelham, A.M. (2013). Does salesperson perception of the firm-level of market orientation influence sales behavior and performance attributions? Journal of Managerial Issues, 25(4), 381-400. Diperoleh dari http://search.ebscohost.com/login.aspx?direct=true \&AuthType=ip,shib\&db=pbh\&AN=96087 $759 \&$ site $=$ ehost-live $\&$ scope $=$ site $\&$ custid $=$ ns 003811

Singh, R. \& Das, G. (2011). The Moderating role of selling experience on the relationship between job satisfaction, adaptive selling behaviors, customer intention, and salesperson`s performance. The proceding of the ANZMAC, 376. doi: 10.1108/JBIM-08-2018-0233

Singh, R. \& Das, G. (2013). The impact of job satisfaction, adaptive selling behaviors and customer orientation on salesperson's performance: Exploring the moderating role of selling experience. Journal of Business \& Industrial Marketing, 28(7), 554-564. doi: [10.1108/JBIM-04-20110121]

Spiro, R.L. \& Weits, B.A.W. (1990). Adaptive Selling conceptualization measurement and nomological validity. Journal of Marketing Research, 37, 61-72. Diperoleh dari http://www.jstor.org/stable/3172551

Tawinunt, K., Phimonsathien, T., \& Fongsuwan, W. (2015). Service quality and customer relationship management affecting customer retention of longstay travelers in the Thai tourism industry: A SEM approach. International Journal of Arts \& Sciences, 8(2), 459-477. Diperoleh dari https://search.proquest.com/openview/ab698719082bd800a5097f82af1480ce/1?pqorigsite $=$ gscholar $\& \mathrm{cbl}=626342$

Toyese, A.Y. (2014). Customer relationship management and customer loyalty in Nigerian telecommunication industry. Journal of Business and Retail Management Research (JBRMR) 8(2), 1-7. Diperoleh dari www.jbrmr.com

Udayana, I.B.N., Farida, N., \& Ardyan, E. (2019). Selling relationship quality to increase salesperson performance in the pharmacy industry. International Journal of Services and Operations Management, 33(2), 262 - 285. doi:10.1504/IJSOM.2019.100289

Vij, S. \& Farooq, R. (2015). The relationship between learning orientation and business performance: Do smaller firms gain more from learning orientation? Journal of Knowledge Management, 8 (4). doi: 29J-2015-10-01-01

Wang, X., Wang, G., \& Hou, W.C. (2016). Effects of emotional labor and adaptive selling behavior on job performance. Social Behavior and Personality, 44(5), 801-814. Diperoleh dari http://search.ebscohost.com/login.aspx?direct=true\&AuthType=ip,shib\&db=eoah\&AN=3934 $9863 \&$ site=ehost-live \&scope $=$ site \&custid=ns003811. doi:org/10.2224/sbp.2016.44.5.801

Williams, T. (2000). Networking as a way of gaining business for training consultants. Industrial and Commercial Training, 32(5), 169-172. Diperoleh dari http://www.mcbup.com/research_registers/tdev.asp

Zhang, J.A. \& Walton, S. (2017). Eco-innovation and business performance: The moderating effects of environmental orientation and resource commitment in green-oriented SMEs. $R \& D$ Management, 47(5), E26-E39. doi:10.1111/radm.12241 